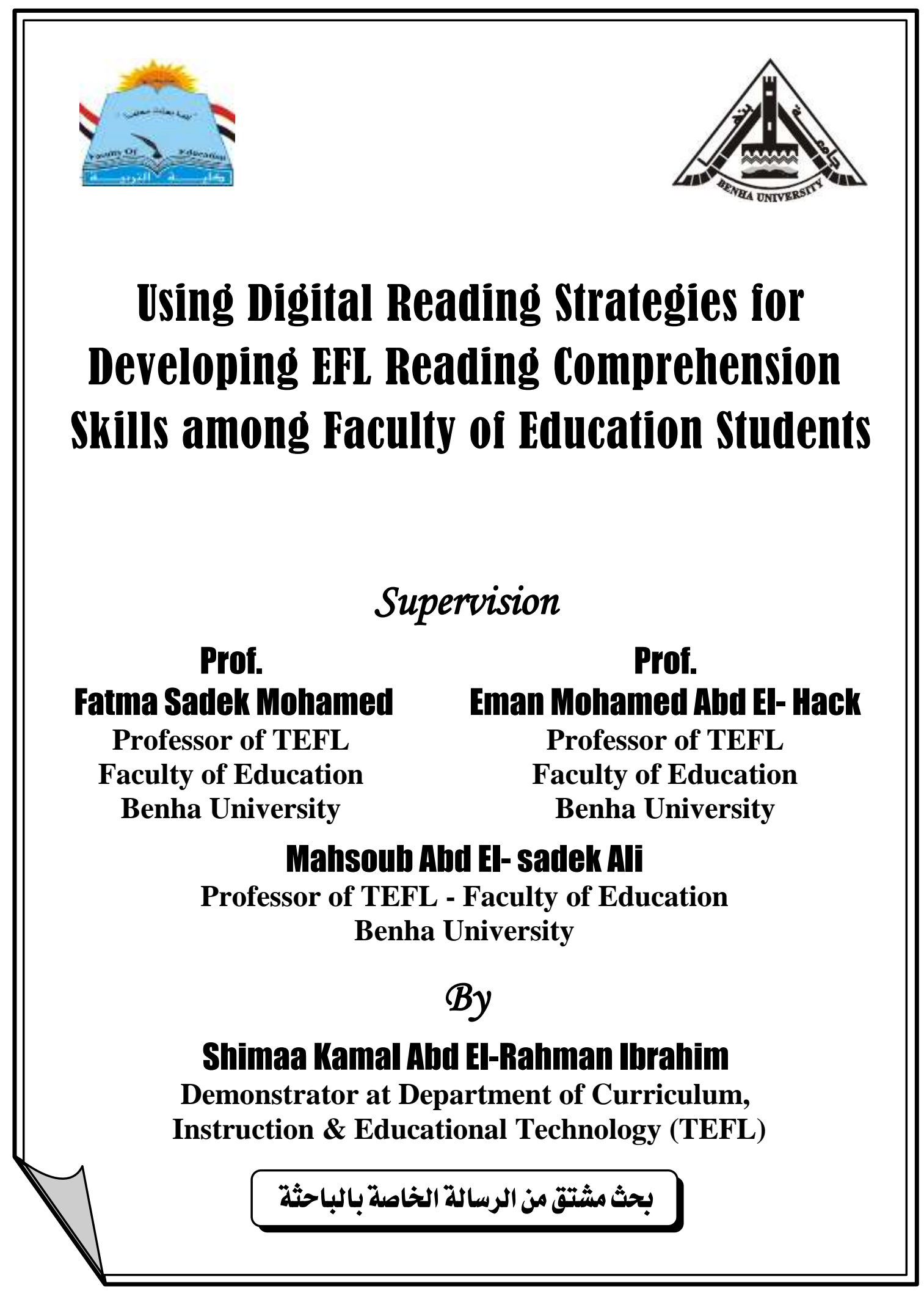




\title{
Using Digital Reading Strategies for Developing EFL Reading Comprehension Skills among Faculty of Education Students Supervision
}

\author{
Prof. Fatma Sadek Mohamed \\ Professor of TEFL - Faculty of Education \\ Benha University \\ Prof. Eman Mohamed Ahd El- Hack \\ Professor of TEFL - Faculty of Education \\ Benha University
}

\section{Mahsoub Ahd El- sadek Ali}

Professor of TEFL - Faculty of Education

Benha University

By

Shimaa Kamal Abd EI-Rahman Ibrahim

Demonstrator at Department of Curriculum,

Instruction \& Educational Technology (TEFL)

\section{Introduction}

Reading is one of the important language skills for learners. Learners need to develop their reading to be successful in learning. Regardless subject matter taught, learners should be able to read and comprehend what they are reading. The foundation for proper education is good reading skills. It is an essential activity in acquiring aspects of knowledge. Reading is the visual recognition of symbols, letters, words and sentences. Learners in non-native language ought to raise their effort for developing EFL reading skills (Alan, 2011; Alla \& Adam, 2013).

It is the process of constructing meaning by the interaction with the text. Learners use prior knowledge and clues to understand the text. Reading is individual activity .Students read in different levels according to difficulty of English. Readers can discuss meaning with writers of the text. Learning to read not only improve the quality of knowledge, but also achieve successful study of text and success in all academic subjects (Abdel-Hack, 2008; Reaku , 2013).

\section{1}


Comprehension is an important factor in reading. Comprehension means understanding what learners read and the meaning of the text. Comprehending a text leads to understanding. So, Learners should know the purpose of their reading and have strategies for reading to understand the text, also the strategies of problem solving. understanding makes students able to paraphrase the passage in their words .

Reading comprehension is the dynamic interaction in the text and content among readers. Reading comprehension depends on the reader, text and the activity. Learners interact with the text in different ways according to their ability to activate knowledge and experience. Text is constructed to include printed and electronic texts (Brown, 2009 ; Ali ,2013).

Reading comprehension is the essence of reading and an active process that reader can interact with the text. It means the process of extracting and constructing meaning through involvement and interaction with written language. Reading comprehension is complex process .Learners cannot understand without knowledge of words and interaction between reader and text. People use the words which they extract and construct to emphasize both the importance and the sufficiency of the text as a determinant of reading comprehension. Reading Comprehension includes three elements. The text which can comprehend, The reader who is doing the comprehension, The activity in which comprehension is a part (Ali, 2013; Helwa, 2010; Snow,2002).

Reading comprehension skills are important because it achieve students' success .Students can be successful in all school subjects. It is also regarded as a cognitive input behavior for all courses. It has significant attention on reading development .It affects on individual differences which influences by stability that continues through reading course. There are many factors affect on reading comprehension skills such as correct reading, fluent reading, word repertoire and invention. Reading accuracy is important predictor of reading comprehension; also spoken language has additional factors for reading comprehension. (Bayat, 2017; Freed, Adams \& Lockton, 2015; Soden et al.2015). 
There are many strategies can help students to comprehend as books and journals because techniques of comprehending are rare in classroom. Teachers need to design lessons to help students to comprehend. Teachers should use specific texts to develop comprehension strategies that students need in different kinds of texts. Teacher may find the ways to connect techniques and reading instruction in all content area of reading (Gill ,2008).

Reading stages can be classified into three stages: Pre-reading, During-reading and post-reading; Pre - reading stage: Teacher activates students' background knowledge and connects what they already know with what they are learning in the school .Teacher helps students identify the structure and organization of ideas in the text. (D'arcangelo , 2002); during-reading stage: learners identify new information in the activities, explaining similarities between new information in the text and what they already know. Reconciling information in the text that contradicts what they already know. Forming questions about what they cannot know and rechecking the text for the information (Roit, 2015). Post-reading stage: students summarize the text after reading it, evaluating the text, stating the main idea and the topic of the text (Paptga \& Ersoy, 2016).

Block , Rodger and Johnson (2004) cited in Abd- El Maksoud (2012) identified four main levels of reading comprehension. Literal comprehension: Comprehension includes surface meanings in this level .It means deducing details from the text and recognizing the purpose of the author. Students should have obvious understanding of the text; Inferential or interpretive comprehension: In this level, students have complete mental process to think about text, relate it to their personal experience and connect it to information. Students must have deeper meanings by making connection between textual information and their thoughts. Critical comprehension: Ideas and information of the text must be evaluated. Students have information accurately. Students can be tested in some skills such as: the accuracy of information and differences between facts and opinions; Meta-cognition: Learners think 
creatively and control their learning .students get rid of difficulties that face in comprehension and reflect it on learning process. Learners have explicit instruction on metacognition. As indicators, researchers have conducted several studies for improving reading comprehension skills using different approaches and strategies such as Al-shaye (2002), Kolicvehoc \& Bajsanski (2006), Abdel Hack (2008), Guo (2008), Hassan (2015), Al -Musawi , Kazem , Al- Hashmi \&Al- Busaidi(2016), Erdal \& Ali (2016) and Ibrahim(2016). There are many effects of technology in reading comprehension and changes in teaching reading comprehension. Reading is a complex process which is affected by material conditions and variables. Practices of readers change according to different situations which they read. One of these changes: the available technologies. Learners take part in technologies in $21^{\text {st }}$ century without instruction: they are writing, reading, and producing texts with multimedia in variety of purpose and contexts (Delima -Lopes, 2013; Morris, 2016; Maynard, 2016 ;Young \& Kajder, 2009).

There are some changes in the context of reading appeared by new forms of reading text such as PDF files, Websites and e books. These devices have importance in reading and readers' behaviors. Students use digital technologies depending on variables and digital readers. There is a role of digital videos in English language classroom. Texts and pictures give meaning with accompanying digital videos, book trailers, music videos, screen casts and others. Students read texts in digital formats. One of all technologies is digital reading (Delima-Lopes, 2013; Maynard, 2016; Morris , 2016 ; Young \& Kajder,2009).

The word" digital" means transforming from print-based text books to digital texts. It means the chance to incorporate meaningful learning strategies and metacognitive activities into texts. In this study, Learners read digital, expository text accompanied by a photo. The reader paraphrased and confirmed the relationships between prior knowledge and level of self-regulation on reading comprehension (Reid \& Morrison, 2014). 
Digital reading is electronic texts that have been transformed to increase access, support comprehension and extend meaningful contentarea learning. Well -designed digital reading scaffold students' literacy learning with multiple means of representation, multiple means of expressions, and multiple means of engaging with text. Digital reading shows how students reading changes with different devices. Students become aware of using digital annotation technologies in different situations (Delima-Lopes, 2013; Meyer \& Rose, 1998).

Digital reading means reading text on electronic screen accompanied with videos, images and graphic .Learners can navigate from page to page with navigation tools. Learners use variety of tools and devices on computers and smart phones Digital reading depends on reading hypertext. Hypertext is the result of computer programming so that text can read non-linearly. The reader can go from page to another to achieve nonlinear then goes immediately to another web page and reads more about that hyperlink. If that second page has hyperlinks, a reader may click on any or all of them too. This type of programming allows the reader to continue in reading. The reader can click on hyperlinks in variety of ways of reading; therefore, every reader may have a different reading way. It is non-linear, non-ordered reading that is so different from reading paper text (Sandberg, 2011).

Digital reading is a new form of information for receiving information and products related with digital press and variety of devices. So, reading contents and reading methods have been always developing into perfection. So, humanization of digital reading design is no more limited in reading hardware. but, It also meet users' practical and aesthetic requirements by good-looking and simple operating system. Information is received effectively and correctly (Yan, 2011).

Digital reading means dealing with reading online or eBook .Reading from screen is different from paper reading behavior .Digital reading relies on book navigation, transforming from reading patterns 
which is linear to e Book or nonlinear. One of these tools is Bookmate .It is a popular digital reading tool. It includes classical novels. There are three aspects of reading: reading schedule, reading speed and book abandonment ( Braslavski , Petras , Likhosherstov \& Gade ,2016). .

Campbell (2016) mentioned that National Council of Teacher English (NCTE) supported students' reading skills. The most important reading books by reading digital texts and multimodal ways of reading; it is clear source of digital reading. Digital reading means allowing students choose digital texts . Students interact with digital text. Students find new and different tools that aid comprehension and response. Students use digital tools like Google Docs, e-book and annotations make them answer text. Students can engage in tools .teacher helps student in choosing text and digital reading tools. Digital texts are texts on the internet which present students and teachers with new opportunities and challenges to extend traditional reading comprehension to new contexts for learning and demand different sets of literacy skills and strategies that were not covered in reading and language arts in the curriculum Digital texts might include one or all of the following:

Explanatory support: student can click on a word or phrase in the text and the computer that helps clarify the meaning.

Presentational support: A student can customize the look or feel of the text by changing color, font, style, or layout.

Illustrative support: A student can supplement words in texts by selecting from series of pictures or a movie to explain concepts as in science as photosynthesis or events in social studies like colonial times in America.

Translational support: A click can adjust the readability level of the text, or change the text from one language to another (Anderson Inman \& Horney, 2007; Coiro , 2003).

Digital reading increases learning interest and support learning, they engage in collaborative inquiry based learning and have motivation 
for reading, Learners become more active and raising learning outcomes .Learners read digital texts, new paper articles and book excerpts. Topic knowledge was assessed through reading digitally. Students express which medium that they comprehend best. Reading digital text can change the way students read affecting on reading comprehension. The researcher showed that reading digital text which means reading with electronic distractions such as (cell phone, tablets and iPods) and reading with internet has an effect on reading comprehension skills. (Chen, Leng, Xu \& Gu, 2014; Singer \& Alexander, 2016; Williams, 2015).

There are advantages of e book in digital devices :quick to obtain and use. Traditional book involves spending time and money or ordering it online and waiting for its arrival by traditional service. For digital reading material, in the research engine ;type words for the title, author, or other information about the book on the internet, read the content of ebook free of charge and discuss the book on online (Lui, 2009)

Moreover, there are online reading strategies include: using hypermedia, using computer applications and accessories, dialoging, setting up reading purposes and planning, Connecting prior knowledge and experiences with texts and tasks, previewing and determining what to read and inferring (Ho-Ryong \& Deoksoon, 2011).

According to Voorhees (2011). There are many platforms in digital reading which are available for reading comprehension. These platforms were selected for presenting content. Google Books: as interface for reading and find print copy of the book, Tresssaver: editor to content's style, most designerly, find and read the article from online publication. Open library Reader: scan for pages and navigate to read pages.

There are some available applications for digital reading instructions as Kindle (Amazon), Read works digital, Acrobat Reader, Roucke and LEAD 21: Read works is a free online platform mainly concerned with improving reading comprehension skills. It includes reading comprehension texts at the different levels. It has largest, 
highest-quality library on nonfiction and literary articles, designed to support reading comprehension. It also includes thousands of downloadable teacher materials for digital reading such as reading passages, lesson plan, vocabulary learning and reading comprehension questions. Readworks create world-class content, teacher guidance, and integrated tools that improve teacher effectiveness and student achievement. It aims at improving reading comprehension with formative assessments, individual student data, and proven teaching tips. It has been used by many EFL learners in different countries: USA, Canada, India and Saudi Arabia (www. Readworks .org).

Kami: An application online or offline for practicing digital reading strategies such as highlighting, note taking, Insert image and strikethrough. It is PDF and document annotation. (www.kami.com).

Exactly: It is an online dictionary for practicing digital reading strategies as looking up new words on line through the context. (www.Exactly.com).

There are many studies which dealt with digital reading. Chen , Leng , xu \& Gu (2014) and Dizon (2014) investigated the effect of using digital reading on reading motivation among students in 1-5 grades .The researcher used survey and test scores .The results showed that digital reading program has an effect on reading motivation.

Terra (2015) and Kurata , Ishita , Miyata and Minami (2017) showed the effect of using digital reading or print material on reading format preference and behavior among undergraduate students. The researcher used survey with 262 answers . The results showed that reading with digital has an effect on reading format and preference.

Chang and Huang (2013) the study showed the impact of digital reading in high academic and educational value among 415 students. The researcher applied a pilot study. The results showed that digital reading has an effect on academic and educational value by using internet and platforms. Nauman and Salzer (2012) investigated the impact of digital 
reading proficiency by using computer based assessment among students in secondary school. The results indicated that students use computer for reading digitally. Kurata, Ishita, Miyata and Minami (2017): the study investigated reading behavior and the impact of digital or print material. The researcher used a survey for 1,755 participants ranging from 18-69. The study showed that learners preferred reading with digital media favored print media.

\section{Context of the problem:}

To document the problem of the study, the researcher conducted a pilot study to investigate the lack of EFL reading comprehension among EFL second year students at Faculty of Education, Benha University. The researcher used an EFL reading comprehension test prepared by Helwa (2010) (see appendix (A) and rubric to score the test see appendix (B). The participants consisted of 20 second year students .The results of the study showed that students lack the main reading comprehension skills. This reveals that there is a lack in students' EFL reading comprehension skills among second year students at the Faculty of Education. . Thus, previous researchers proved or showed that there is a lack in EFL reading comprehension skills such as (Helwa, 2010), (Abdel -Maksoud , 2012), (Ali,2013), (Youssef , 2014), (Hassan, 2015) and (Ibrahem,2016). In spite of the importance of EFL reading comprehension skills, there is a lack in these skills among EFL second year students at faculty of Education. Most university students suffer from reading comprehension skills. Students cannot read authentic text comprehension well. Students should have the opportunities to practice these skills in and out the classroom.

Out of the researcher's experience in teaching, it has been noticed that there was a lot of problems that hinder EFL second year students during reading comprehension such as students can't differentiate between facts and opinions, answer questions, identify the main idea, 
connect the text meaning to students' previous knowledge ,inferring cause and relationship and giving the appropriate meaning of key words .

Therefore, the present study aims to investigate the effectiveness of using digital reading for improving reading comprehension skills .Students use devices and tools on tablets or computers to understand text comprehension by reading digitally.

\section{Statement of the problem:}

In spite of the importance of EFL reading comprehension skills, there is a lack in these skills among EFL second year students at faculty of Education.

\section{Questions of the study}

To face this problem, the present study will attempt to answer the following questions:

1- What are the EFL reading comprehension skills required for second year university students?

2- What are digital reading strategies required for developing EFL reading comprehension skills among EFL second year university students?

3- What is the effectiveness of using digital reading strategies on developing some EFL reading comprehension skills among EFL second year university students?

\section{Delimitations of the study}

The present study can be limited to the following:

1- A group of second year university students.

2- Some EFL reading comprehension skills required for second year university students.

3- Some digital reading strategies (Highlighting, Strike through , Insert comments, Images, Videos and annotation. In addition to using electronic dictionary.

4- Some electronic tools (Read works digital- Kami -Exactly). 


\section{Participants of the study:}

The participants of the present study will be EFL second year students in English section at the faculty of Education, Benha University.

\section{Instruments and materials of the study:}

A reading comprehension test (pre-post test).

\section{Significance of the study:}

The significance of the present study lies in what it will offer to the following groups.

\section{EFL second year university students:}

1- Developing some EFL reading comprehension skills.

2- Providing students with some digital reading strategies which helps them develop their reading comprehension skills.

3- Helping students interact with each other through digital reading.

4- Encouraging them to use technology in reading comprehension.

\section{EFL teachers:}

1- Providing them with a list of EFL reading comprehension skills necessary for students.

2- Providing them with applications for assessing EFL reading comprehension skills.

\section{Curriculum planners:}

Paying their attention to digital reading in reading comprehension and teaching its strategies in the EFL curriculum.

\section{Other researchers:}

- Providing them with some digital reading strategies for developing EFL reading comprehension that can be used to investigate the relationship between EFL reading comprehension and other variables. 
- providing them with a list of EFL reading comprehension skills and tools for assessing EFL reading comprehension.

- providing them some references to return them.

\section{Procedures of the study: $\square$}

The following procedures will be followed by the researcher to answer the questions of the study:

\section{1- Identifying the EFL reading comprehension skills required for second year university students:}

- Reviewing the literature and previous studies related to EFL reading comprehension skills.

- Preparing a list of EFL reading comprehension skills required for second year university students.

- Submitting this list to a panel of jury to verify its validity.

- Modifying and setting the final form of the list according to jury point of view.

\section{2- Identifying the digital reading strategies for developing} students reading comprehension skills through:

- Reviewing the literature and previous studies related to the digital reading.

- Identifying the objectives of digital reading.

- Identifying the content of digital reading.

- Identifying the teaching strategies and techniques used in digital reading to develop EFL reading comprehension skills.

- Determining the evaluation techniques that will be used.

- Preparing the instructor's manual as a guide of how to use digital reading for developing EFL reading comprehension skills.

- submitting the manual to jury to verify its validity.

- Modifying the instructor's manual in its final form according to the final modifications. 


\section{3- Identifying the effectiveness of using digital reading} strategies in developing EFL reading comprehension skills:

- Designing the study instruments and verifying their validity and reliability (EFL reading comprehension skills test).

- Selecting the participants randomly of second year university students at the faculty of Education, Benha University.

- Dividing the participants into two groups: experimental group and control group.

- Administering pre-test to two groups before teaching with digital reading.

- Teaching the experimental group with digital reading application (online/offline) while the control group is taught by the usual method.

- Applying the EFL reading comprehension skills post-test to the experimental and control groups after the intervention to measure the effectiveness of digital reading.

4- Collecting the data of the study and conducting statistical analysis of the data.

5- Analyzing the data of the study.

6- Interpreting the data of the study.

7- Presenting recommendations and suggestions.

\section{Terminology:}

\section{Reading comprehension $\square$}

It is the process of extracting and constructing meaning through interaction and involvement with written language. We use the words extracting and constructing to emphasize both the importance of the text as a determinant of reading comprehension (Snow, 2002).

Is an active process that reader can interact with the text. It means the process of extracting and constructing meaning through involvement 
and interaction with written language. Learners cannot understand without knowledge of words and interaction between reader and text. It includes three elements the text, the reader, the activity in which comprehension is a part (Ali ,2013; Helwa ,2010).

The operational definition: it is an active process that the reader can interact with the written text through the ability to extract and construct the meaning from the text. So, reader can understand the elements of the text, identifying the idea and extracting meanings through context.so, the interaction between the reader, the text and identifying direction of the writer become a determinant of reading comprehension.

\section{Digital reading:}

It means reading from the screen, there is variety of screens from which to choose. Digital reading can take place via computer screen. One of the first digital consumption tools with the advent of the personal computer and then the internet via personal digital assistants (PDAS) and smart phones screen, and most recently via e Reader and tablet on screens (Kesterson , 2015).

It means students read digital texts. Learners interact with digital text. Learners find new and different tools can aid comprehension and response. Learners use digital tools like Google Docs, e-book annotations answer text. Learners can engage with tools and teacher helps student in choosing text and digital reading tools (Campbell, 2016).

It means reading text on electronic screen accompanied with videos, images and graphic .Learners can navigate from page to page with navigation tools. Digital reading depends on reading hypertext. Hypertext is the result of computer programming, so the text can read non-linearly. The reader can go from page to another to achieve nonlinear then goes immediately to another web page and reads through hyperlinks. If that hyperlinks mean reader may click on word or all of them also, the reader can click on hyperlinks in variety of ways of 
reading; different reading way. It is non-linear, non-ordered reading that is so different from reading paper text (Sandberg, 2011).

It means online reading of news, blogs ,Twitter messages ,e-book and electronic magazines in addition to words and pictures, it includes supporting content with audio and videos features and making reading more entertaining (Hui, 2009)

The operational definition: It means reading texts from the screen, personal computer or Lap tops or smartphones or tablets. Reading text in digital is different from reading on paper is accompanied with vidos, images, graphics and listening to the text which support the content. Reading is for news, blogs and e-book. Reading is nonlinear to hypertext. It means transforming from link to another link and from web page to another with some strategies as highlighting, insert images, make comments, strikethrough and login hyperlinks that the reader can click on.

\section{Review of literature and Related Studies}

\section{Section one: Digital reading}

\subsection{Introduction:}

Digital reading is a new term used in the literature in the last few years. There are three terms which may be similar. These terms include "digital reading", "online reading" and "web- based reading". These three terms depend on the internet access. In that research, these three terms will be used interchangeably.

\subsection{Definition of digital reading:}

It means reading text electronically accompanied with videos, images and graphic .In digital reading, learners can navigate from page to page with navigation tools. Digital reading understood as reading hypertext. Hypertext is the result of computer programming, so the text can read non-linearly. The reader can go from page to another to achieve nonlinear, then goes immediately to another web page and reads through hyperlinks (Sandberg, 2011:3). 
Digital reading means reading on computer screen, there are several screens which learners can choose. It takes place via computer screen. It depends on digital tools. These digital tools are personal computer, internet, personal digital assistants (PDAs) and smartphone via e-reader and tablet. These tools are used professionally and personally (Kesterson, 2015:28). Consequently, digital reading become well-spread in schools as learners were interested in to access internet to acquire information relevant to their subjects (Organization for Economic Cooperating and Development :1 2015).

Digital reading means that readers jump and skip through texts and media in form of hyper-reading. It is browsing and scanning as one time reading but nonlinear. It is human ability in written language accompanied with technologies as scroll, codex, hypertext and web. Reading behaviour of human on the web gives interaction of print materials to be faster and less linear and movement between texts increasing implications of digital reading. Digital reading means scanning of topic altering. (Freund, Kopak, \& O'Brien, 2016:79)

Digital reading means the digitalization of reading skill. It has the digital action of reading skill. It has two meaning: reading object that means content of the reading in digital formats, networks, novels, electronic maps and books, digital photos, bogs and web pages. The second is reading method on the screen which displays instruments as PC, PDA, MPU, MPS, lap tops, e-readers and mobile phones. (Jinpin \& Yongqiang, 2018: 1)

\subsection{Features of digital reading environment:}

In digital reading, digital readers have more capacity for supporting teaching and learning for understanding structure, comprehension strategies and literacies which give opportunities to differentiate the reading process for needs of individual and purposes. Digital readers use digital dictionaries, highlight and took notes, conduct internet research, fonts and use multiple apps to have deep structure of comprehension strategies and literacies (Pryor, 2013:4). 
In digital reading environment, there is shifting from applications such as email and social networking sites. There is shifting to multimedia as web-based text, images which describe text, also encourage reader to read and understand the text. Digital reading establishes as activities alone or connects between web searching and online activities. The major focus on the effect of digital reading on comprehension. The use of hypertext is difficult to assess the length of texts. (Freund, Kopak \& O'Brien, 2016:79)

\subsection{Strategies of digital reading:}

Digital reading strategies include surveying, resource fullness and navigation. The navigation makes reading flexible and incorporates with careful reading, skimming and ignoring text which is not needed in the reading purpose. Prior experience in technology improves efficiency and making decision. Inflated sense of self-efficacy makes readers lacking metacognitive skills to reflect while reading digitally. The findings give possibilities for developing effective online reading comprehension assessment and instruction (Dembroski, 2014:7). There are digital reading strategies. Pre- service teachers use these strategies when reading on e-text book in literacy method course. Learners use e-text books due to it is becoming relevant to mobile devices and acceptance of e- book and high cost of print text books. Student need to be fully comprehension of text. So, teacher should have awareness of e-text book features and the process for reading text with web links, audio files and video clips. The participants in this study developed their cognitive engagement to use e-text book and engaged with media- as well as text. Others found that reading e-text book challenging. Because there are distractions on their devices, eye strain and over-whelmed with choices. The findings of the study showed that learners expressed choice between using print or electronic format or both. (Dobler, 2015:482) 
Since technology assists reading, there are varieties of strategies which readers employ according to their needs. Readers "type the word in search box" and they search online dictionary. Then, readers do not wait dictionary appear the meaning, they use" Goggle map" to search for and find sites, discuss in the passage and zooming the map. These strategies called digital strategies accompanied with using dictionary and scrolling text. (Zarrabi, 2015:125) There are tasks on digital reading as scrolling, navigating and hyperlinking. (Freund, Kopak, \& O'Brien, 2016:79)

Reading is changed when they read digitally. Readers use strategies in texts as highlighting, sticky notes and index cards. They have options to interact with the text. They tape on the screen to learn definition, highlight passage by swiping, underline with annotation tool. So, readers are able to annotate, color code and take notes without entering back to look for study tools. Consequently, annotation is key factor to achieve deeper understanding. Annotation is used with colours to indicate thinking as making circles in yellows as having question. Teacher encourages students to take notes to achieve reading with purpose. Readers underline words in case of having puzzling statement or jot question. They can underline in orange when they want to make self-text connection. (Burn, 2016:1)

In digital reading, students navigate through hyperlinked pages to finish information and searching for tasks. Learners visit one page or more pages to be successful and negotiation of various pages. Students seek for information online by reading news and had more success at navigating. Digital reading requires complete tasks successfully and efficiently. It requires learners spending a lot of time on clicking links and using online spaces as places for social engagement as email, chats and social media. The findings assured the importance of navigating online text more than social purposes. (Naumann, 2016: 263) 
In addition to the previous strategies, readers can comment on collaborative document. They can read two texts in the same time by arranging windows side by side. Readers can look up words on dictionary through Google search. Taking screen shots by using keyboard shortcuts. They can download apps or document by PDF. Readers who cannot see the text, they can zoom in text by selecting on screen buttons, using gestures on touch or keyboard shortcuts and adjusting the bright of screen. They also can type the full address of website, using bookmark and make navigation. Furthermore, they can load play video games on computer. They can highlight and track to assure reading. They use multiple tabs in browser to arrange texts, refresh pages and update information by clicking with digital stylus. (Zucker, 2018:63)

\subsection{Programs and platforms in digital reading strategies:}

Myberg and Wiberg (2015:49) stated that there are some platforms as Blue Fire Reader in Android user: It allows downloading PDF files on your device and using PDF files. Erbary Reader is another online application. It is suitable for tablet. The text can appear but learners cannot highlight or underline text. Consequently, when learners try to underline or highlight, they move the whole text sideways. Digital reading programs are useful for literacy: language and literature learning or teaching. (Ebrahimi, 2016:112)

As mentioned before digital reading programs use to make navigation across pages through hyperlinks to assure comprehension of text and avoid distraction (Salmeron \& Liorens, 2018:2).So, there are some programs for performing digital reading strategies. One of these programs is a program combining eye-movements modeling Pryor. The program used with students' in $9^{\text {th }}$ grade. Learners plan, evaluate and monitor digital reading in the programme depends on EMMES. They have videos of oral transcription of thoughts and model when answer 
questions in hypertext. Learners achieve high scores in comprehension in post-test after following instruction with comparison to control group studies with following instruction with written text. Learners work with EMMEs spend more time in reading digital document. (Salmeron \& Liorens, 2018:1).

\subsection{Importance of digital reading:}

Coiro (2005:30) mentioned that digital reading helps readers to stay on task. Learners acquire information sufficiently and communicate with using technology to be successful in knowledge for school. Digital reading has great interest in digital libraries, especially in reading experience. The data shows the patterns of digital reading involve what and where users read and how readers perform in their reading sessions.

Digital reading platforms have importance in comprehension; activate reader's engagement and human information interaction (Freund, Kopak, \& O'Brien, 2016:79). Learners become more confident and achieve better understanding when they read digitally. Learners in digital reading write down keywords that help in learning. Another form is happening in digital hardware and software screen on computer achieves less eye strain, annotation in programs improves. Digital reading devices accompanied with tools enable learners to digital move from page to page and variety place marking (Baron, 2016: 5:6). Digital reading makes learners choose the materials depended on the level of proficiency and interests. Learners should achieve understanding in reading. Digital reading is based on independent reading and individualism. (Ebrahimi,2016:112)

According to Ebrhimi's study(2016:113:114), digital reading helps students' reading comprehension of literacy texts. The participants were 30 students of four classes. Two of these classes were EFL English college students with upper intermediate level of proficiency. The other two classes were students in ESL English classes of upper intermediate level of proficiency. The participants were in Iran in EFL context and 
Malaysia in EFL context. The findings showed that digital reading is effective for reading comprehension of literary texts by EFL and ESL readers. (Ebrahimi, 2016:113:114)

Knowledge in digital reading is achieved and constructed in interaction with information in sources which have by the reader. Digital reading text interacts with the reader skill to influence performance. Digital reading is an end point on spectrum. It achieves reading multiple texts and gathering information on the internet. (Barzillai, Thomason, Schroeder \& Den-broek, 2018:10)

\subsection{Benefits of reading texts digitally:}

With the interest of digital text structure, there are dimensions to achieve success in school and independent learning environment. Learners treat with hybrid text structures. These require interactivity, analysis and evaluation. Learners try to apply knowledge towards problem solving. Learners compare, seek, assess and evaluate information from online sources. (Ortlieb, 2014:258)

Digital reading differs from reading print text. Digital reading is broader. The new technologies changed the notion of the meaning of what we read. Although it was supposed that learner's attention is more when they read print rather than online, but now they conceive that print is boring. Reading print text starts to diminish. Online technology is made for searching for information than analyzing ideas. When you read digital screen, it affects learner's attention on words and ideas. (Baron, 2017:15)

The implication of digital revolution to show how students read, write and access information. The number of assignments achieves reading on digital screen. Encyclopedias give students the opportunities to online search. The nature of reading is changing from print text to digital text. Reading digitally is reading on digital device as look up address, send a Facebook status update and grab the news headlines. Learners read on laptop or e-reader, tablet or mobile phone to move pages. (Baron, 2017:17) 
The annotation of digital texts make users add information, share ideas and create knowledge. Annotated content helps learners to understand digital text and content. The paper introduces novel annotation system with annotation multimedia as text annotations, picture annotation, video annotation and voice annotation which embedded in HTML webpages that students add and manage annotations on pages and shared annotation on pages by using application as CAS. (Chen \& Tsay, 2017:1122)

\subsection{Types of digital reading:}

There are four types of digital reading. Annotation has types as physical annotation and digital annotation. It means informal marking by the user while reading and making sense of the text. These markings are notes, digital annotations and scribble, also highlighting, underlining, circling and doodling. (Pearson, Buchanan \& Thimblebky, 2013:59)

Note taking achieves active reading process. Digital note taking has examples as space, tool overload and menu navigation. It uses as function which splits into two distinct tools: digital placeholders and digital annotation. (Pearson, Buchanan \& Thimblebky ,2013:71)

The search of web page in digital reading achieves results is the form of hyperlink when click on will take the user into appropriate page and highlight the key word and phrase on pages. Tool tips: It shows to the user of the relevant pages in the list and the exact number of text matches on page by putting mouse over hyperlink. (Pearson, Buchanan \& Thimblebky, 2013:85)

Comprehension of digital text depends on types of digital text as hypertext without or with graphical navigable overviews. Graphical navigable overviews facilitated reading comprehension for readers have lower prior knowledge. The conclusion assured that hypertext with digital text and reading compression question are easier than linear digital text. Factors predict reading comprehension of linear text, hypertext and graphical overview helps learners when they have low prior knowledge. (Fesel, segers \& Verhoeven, 2018:107) 


\subsection{Digital Reading Practices and proficiency :}

The practices of digital reading mean that learners read through websites and audio-taped dialogue. There is transcribed to recordings and notes taken after reading 40 minutes. Learners navigated the sites. The study used observational data along transcribed interview. (Rowsell \& Burke, 2009: 108)

The contexts of digital reading affect reading practices, students use digital devices to read. The representations of digital reading cannot distinguish between context and genres of reading. Students use digital techniques. The study uses survey and interviews to show how students reading practices change with different devices and situations. Students depend on laptops and smart phones in their communication. Reading instruction is performed in variety of ways and their practices change with different contexts. In the study, The researcher uses assignments to help students to be aware of practices in different situations and the ability to use digital annotation technologies. (Morris, 2016:3)

Reading practices in the $21^{\text {st }}$ century depend on concentrating onscreen reading in technological age. There is insight into the nature of on-screen reading and the authentic on-screen reading experiences for post-graduates students. There is focus on investigation of participants' reading comprehension strategies, processes while reading on-screen articles and make comparison to those who engaged in print reading. The students use digital abilities and on-screen reading. The objective of Khadawardi's study is to examine students' preferences of both reading print and digital format. The data collected by using questionnaire, think aloud protocol, field notes, recall and interviews. He used thematic, content analysis and constant comparative method to analyze data. The findings of the study showed that to achieve on-screen reading, multiple literacies are required, and this includes a newly identified digital academic strategy literacy. Learners identify digital strategy literacy. The results demonstrated that transfer from print reading to on-screen reading 
and from traditional literacy to digital which readers use strategies in order to read on-screen. Practices suggested that lessons in $21^{\text {st }}$ century transform skills from text books to reading digitally on screen. It is useful for teachers when teaching on screen reading strategies for academic Purposes. (Khadawardi, 2016:1)

Kurata, Ishita, Miyata \& Minami (2017) mentioned that in digital age, daily readings become digital reading. They used survey to inquire about reading behaviour and preferences. Therefore, the transforming in reading from print media to digital reading media. There is focus on reading behaviour for media and reading preference between print and digital in different conditions. The participants were men and women from five ages from 18 to 69 years. The findings were $70 \%$ for reading on digital media and preferred favoured print media. The findings revealed that there is mismatch between reading behaviour and preference either or print or digital media. Naumann and Salzer (2017) studied digital reading proficiency in German. The students were 15 years old at secondary school. The study based on PISA 2012 Computer based assessment $(\mathrm{N}=22785)$. The study used mean performance in digital reading and relation with student background, availability of Information Computer Technology (ICT), use of ICT, and attitudes towards ICT. Digital reading proficiency stays significantly behind print reading. ICT availability and use had relationship with digital reading proficiency. There are models of reading information through (ICT) as digital literacy through differences of this literacy. Digital environment, information literacy and digital reading are the bases of critical thinking and the evaluation of texts on media.

\subsection{Tools and technology in digital reading:}

The new digital tools expanded types of texts as videos and info graphics and to communicate content area knowledge. The technology professional development was designed to enhance teacher professional learning. Teacher makes students critical consumers and producers of technology in the $21^{\text {st }}$ century. Learners are searching for instructional 
applications of tools in technology to build literacy. Learners use webbased and digital sources: They interact with resources and texts. Teachers must not only read about web-based and digital resources but they should exploring sources. Teachers and students move forward in digital age. Learners must explore digital resources and using resources in the classroom. (Ciampa, 2016:305)

Braslavski, Petras, Likhosherstove and Gade (2016) examined digital reading devices. One of digital reading devices is using e-book. E-book has an effect on reading patterns and behaviours as it provides search, multimedia and hypertext that cannot be achieved in print. The content in e-book is different from print. Mobile device can support reader with hundred thousands of book titles. The focus on three aspects of e-book: reading schedule, reading speed and back abandonment. So, reading is central cultural practice. Reading $\log$ can be benefit for schooling, second-language and creative writing. Digital reading related to reading online or e-book concentrated on differences between paper reading and screen behaviour. The data was qualitative and use of ebook as interviews, diaries or observations on individual differences and preferences reading online.

E-books allow readers to access books without carrying it. Ebooks have digital rights management systems that may complicate downloading. Readers can read e-books online. They can save their notes and bookmarks. (Myberg \& Wiberg 2015:49) There is a change in educational practices by reading and writing digitally. The research focused on how educational reading practices have combined literacy in digital classroom. Students use personal digital device as Ipads. The participants were 13-14 years old. The students studied through videorecordings. Reading practices changed through digital technology. The educational practices scaffold traditional reading comprehension which is required in digital environment. (Molin \& Lantz-Anderson, 2016:131) 
Szentgyorgyvolgyi, Novotny and Szabo (2017) investigated the effect of digital technology and electronic media on printed media. The researchers used a survey of 32 questions. They compared results of the survey based on responses. The results showed that reading and writing are changing with using technology. There is interaction between paper and digital. The spread of the internet and communication of media also changed the printed paper. Digital technology has entered people's life instead of reading printed paper in newspapers and magazines. They changed reading in new sites and e-books to read books. The results showed that reading and writing functions are changing with use.

In digital reading, readers copy and paste the text with using the mouse, tool bar options or keyboard. They use quick look to have more information without logging new pages. (Zucker, 2018:63)

\subsection{Digital reading applications:}

One of digital reading applications is Book Mate. Book Mate contains business books, politics, romance and society books. The data involves information about books, users and reading sessions. Book Mate contains 523, 689e-books. Book Mate users spent time in reading in the Apps to different books. The participants were males and females. The year of birth to participants range from 1980s to 1990s. The readers read books within observation period. The book length does not correlate with its completion rate. The analysis can be benefit for different applications and domains such as digital libraries. (Braslavski, Petras, LikhosherStove \& Gade, 2016:392)

Learners are no longer reading books in paper but they began to read books electronically they can access book on desktop on computer, tablet, Kindle, on phone by having library at any time or any place. Learners can reach books in seconds as children and reluctant readers. They are motivated to read on electronic reader. (Gibbs, 2016)

There are types of reading and how digital reading replaces reading from printed newspapers to reading on tablets and make 
comparison between two. The effect of medium interface (tablet versus paper) on style of reading and recall information. The experimental study were 90 illustrated that digital replicated were not perceived to be read in selective or fragmented manner than printed. The research showed that digital innovators recalled the same information from reading on tablet as reading from paper in contrast to less innovators readers. They recall from reading on paper than on tablet. (Neijens \& Voorveld, 2016 :760) There are some devices as palmtop device as personal digital assistants (PDAS) for reading electronic text as learning tool for reading. The questionnaires and interviews revealed the impact of PDAs on reading. The PDAs constrained reading with small screen size and navigating through text as take notes, skim and read the text, move back and forth within the document. The PDAs can be used in any time and any place. This is easier for students to practice reading and activities. The learners used PDAs addition to other tools. These tools are not replacement to paper to complement it. The findings showed that the tool modified reading activity. The study used web-based on information and nonlinear with cognitive sources. (Waycott , 2016:38)

The digital content on mobile devices is involving app books, flash animations and augmented reality (AR) books on reading interest for children and concentrating on reading for books. The responsible factors were investigated in the study. The results of the research show that reading and concentration increased by flash animation. Children in the study become more interested by AR books and app books in reading story books but decrease their reading concentration. Comparisons of digital content by using test prototypes that increase reading interest of story link books but prototypes of high level of interactivity have negative influence on children's reading concentration. The findings give recommendations how to design digital content for children. (Wang, Lee $\& \mathrm{Ju}, 2018: 1)$ 


\subsection{Digital text and devices in reading:}

Readers now encounter texts in digital formats. They can read with digital format by making navigation. Readers need to comprehend individual texts and the structure of digital text environment. Reading comprehension and prior knowledge impact on the way that students use the structure of digital text to navigate through content of text. The researchers investigated the relationship among reading comprehension, Prior knowledge and navigation behaviour in digital texts. The findings showed that there was no significant relationship between prior knowledge and navigation behaviour. (Sullivan \& Puntambekar, 2015:299)

The annotation of digital text makes learners able to add information, create knowledge and share ideas. Poor annotation and excessive in digital text make overload in information and reduce attention to the content. Learners work with web-based collaborative reading annotation system (WCRAS- TQAFM) with quality of annotation as filtering mechanisms and master annotation filters to promote reading performance. Digital reading is better when readers read with high grade annotation compared to read without annotation. High-grade annotation enhances reading comprehension of learners in answering questions as recall information; get the main idea, inference and application. (Jiun-chi, Chih \& Po-Han, 2016:81)

Singer and Alexander (2016) explained differences in comprehension between students read digital and print texts. The participants were 90 undergraduates read digital and print of newspapers and excerpts of books on topics of childhood. Topic knowledge was assessed prior to reading texts, and then students asked to express their medium preferences. After reading, students were asked to say which they comprehend best. The results showed that students prefer reading digitally. Performance was not consistent with students' preferences and outcomes. There were no differences when students identified the main 
ideas. Students recalled key points related to the main idea and relevant information when engaged with print. No differences in reading outcomes were found in newspapers or book excerpts.

Martinez (2016) investigated how proficient and non-proficient fifth grade students comprehend digital in qualitative research. The participants were 28 fifth-grade students from elementary school. The research included pilot study. Students interview questions and were asked to describe how they comprehend digital text on computer through reading strategies and digital tools. At the end, students answer questions to assess skills. The findings showed that reading strategies are used by proficient and non-proficient readers. All participants reported that using reading strategies in order to extract meaning in digital text. .

Maynard (2016) concerned about reading comprehension skills in the United Stated. The purpose of the study to investigate the impact of technology on reading comprehension. The method was quantitative and correlation of grade students in school in Maricopa. Students were given pre-test. Students were divided into two groups: One group read print text and other group read digitally after divide them randomly. All students were given post-test. The test is used to analyze collected data.

Digital text is structured as hypertext in the way that readers can navigate from the original page to other pages. Literary and expository texts are considered as hypertexts. Hypertext novels as example for hypertext allows readers to say their own story by make selection from alternative story lines. Expository hypertexts such as Wikipedia which makes readers to navigate through multiple documents. Digital texts have multimedia as sound and dynamic visualizations they are not found in print media. Digital texts are on screen in computer, tablet, an ereader, smart phone or any virtual reality goggle. Technology in texts changes the experience of reading. (Barzillai, Thomason, Schroeder \& Den-broek, 2018:142) 


\subsection{Hypertexts and hyperlinks in digital (online) reading through navigation:}

Hypertext has potential effect to change how learners read and understand text. Hypertext can be benefit for readers in which that readers know best information they need tread and which links in network they follow. Hypertext can create useful and meaningful networks depend on how to divide parts of texts and what segment of text achieves meaningful nodes and what links are important and meaningful what text and meaningful, what texts can read nonlinear. (Hilligoss \& Selfe, 1994 2:5)

Hypertext is more intuitive and natural than linear texts. Readers can get information easing in network more than linear. Hypertexts are better than linear texts for achieving reading and more learning. In hypertext, readers can infer link between sentences of the text. The net has effect on hypertext to give reader more control on information they read. Readers should locate information they need and relate it facts in the internet. (Hilligoss \& Selfe, 1994:7 :17)

Readers select which links in hypertext that contains best information. Therefore, readers should organize information for level of knowledge and purpose of reading. Hypertext promotes browsing and exploration. Hypertext is effective in reading situations. Hypertext allows readers to choose among texts through network. It achieves satisfaction for readers, through more designers of hypertext's system to face challenges among readers. The evaluation of hypertext must be ongoing involve readers with what to read, how much to read and when to read information on the network. Hypertext promotes readers to work. (Hilligoss \& Selfe, 1994:7 :21:34)

Hypertext is the result of computer programming, so the text can read non-linearly. The reader can go from page to another to achieve nonlinear, then goes immediately to another web page and reads through hyperlinks (Sandberg, 2011:91). 
Hyperlinks mean reader may click on word or all of them. Also, the reader can click on hyperlinks in variety of ways of reading; different reading way. It is non-linear, non-ordered reading that is so different from reading paper text. (Sandberg, 2011:91)

There is focus on digital texts in their relationships to hyperlinks. There were results in hypertext (nonlinear). Navigation has affected with hypertext, previous knowledge and comprehension of digital expository text and comprehension of the text. The study assured text structure, previous knowledge, working memory affects on navigation of digital text and comprehension of the text. The participants of the study were 56. They read four digital texts and answered the questions with using working memory capacity. Students adopted navigation behaviour on each text (hypertext versus our network). The results showed high previous knowledge texts led to more pages visited, more non-linear jumps in reading, and more returns to the overview in the Home page in the network help students to engage in reading process. (Burin, Barreyro, saux \& Irrazabal, 2015:529)

Azmuddin , Fariza and Hamat ( 2017:884) explored student's online reading strategies while they read hypertext materials for academic reasons. The participants were 100 students from science and technology courses in university of the East Coast of Malaysia. Data collected with usage of web based survey. The survey consisted of two sections: Internet usage and online survey of reading strategies. The survey was 38 items of likert question measuring metacognitive online reading strategies. The results showed that students use problem solving strategies $(\mathrm{M}=3.66)$ with support reading strategies $(\mathrm{M}=3.29)$. Students use higher order thinking skills when they read hypertext. The conclusion that teachers should teach students online reading strategies while they read hypertexts.

Carolin, Frank, Ulf and Johannes (2017:149) mentioned that students comprehend digital hypertext more than skills in reading linear text. Measures involved reading comprehension via hypertext (digital 
reading) and linear reading text as well as memory. The participants were 15 years old students in German $(\mathrm{N}=288)$. Reader behaviors were derived from log files. The findings demonstrated that memory affected on digital reading over linear reading. The effect was by cognitive reading and individual reader behaviour.

Readers can get information from different sources but information and evaluation requires navigation skills. The participants were 558 students from grades 7 to 10 grades reading on the internet while navigation and comprehension scored. Internet reading's frequency and self-efficacy were assessed in the study. There is analysis of navigation skills increase with grade. Comprehension is based on internet reading achieve to common processes. Finally, internet reading achieves internet comprehension. Reading on the internet has platforms for reading. Internet reading has activities and hypertext documents. The focus on internet tasks and comprehension processes. There is an integration of information from hypertexts and looking for information from webs. (Salmeron, Garcia \&Vidal-Abarca, 2018:31)

The study mentioned that types of digital texts and hypertext is supplied with graphical and navigable overview. The hypertext must conation links and digital text also accompanied with hypertext, hyperlinks and navigable graphical over view. The hyperlinks per page linked to all pages of the next level. In each page there are two or three hyperlinks. (Fesel, Segers \& Verhoeven, 2018 : 112)

Association for Information Science and Technology, 68, 884:894.

\section{Chapter three}

\section{Introduction:}

This chapter deals with the research methodology that has been followed in investigating using digital reading strategies for developing EFL reading comprehension skills among Faculty of Education Students. This chapters includes the following items:

1- Participants of the study. 
2- Research design.

3- Variables of the study.

4- Instruments and materials of the study

a) EFL reading comprehension skills checklist.

b) EFL reading comprehension test.

c) Digital reading strategies.

5- Experimental treatment of the study.

\section{1- Participants of the study:}

The participants of the study consisted of 25 second year English Language section students at Faculty of Education, Benha University in the second semester of the academic year 2018-2019.

\section{2- The Research Design:}

The present study is a quantitive study. The design is quasiexperimental design because the design measures the independent variable and its effectiveness of using it in dependent variable. The present study followed the pre-test and post- test to the experimental one group design for developing EFL reading comprehension skills by using digital reading strategies as treatment in the study among students at Faculty of Education, Benha University.

\section{3- Variables of the study:}

- The independent variable is digital reading strategies. These strategies are scan the hypertext, paraphrase ideas online, highlight phrases, underline words, take digital notes, click hyperlinks, use online dictionary, use tables and pictures online, make digital annotation, summarize and access hypermedia.

- The dependent variable is reading comprehension skills.

\section{4- Instruments and materials of the study:}

This study has an aim of using digital reading strategies for developing EFL reading comprehension skills among Faculty of 
Education Students. The researcher used the following instruments and materials to achieve the purpose of the study:

A) An EFL reading comprehension checklist.

B) An EFL reading comprehension test (the test applied pre-posttest).

C) Digital reading strategies program as a treatment.

\section{A) An EFL Reading comprehension skills checklist (RCSL):}

\section{A.1 The purpose of using EFL Reading comprehension checklist:}

The checklist of reading comprehension skills was prepared by the researcher of the study to identify necessary EFL reading comprehension skills for the second year students at language English section at the Faculty of Education as they study reading comprehension course as specialized students, then the researcher modifies the reading comprehension skills checklist in the final form at the four levels.

\section{A.2 Sources of designing the EFL reading comprehension skills list:}

The sources of EFL reading comprehension checklist main skills and sub skills list were seven studies as El Garwany (2010), Helwa ( 2010), Mohamed ( 2010), Awad (2013), Ibrahim (2013), youssif (2014) and Ibrahim (2016).

\section{A.3 Description of the EFL reading comprehension skills checklist (initial form):}

In the initial form, the EFL reading comprehension checklist in the present study includes three levels of main skills (literal, inferential, critical and evaluation comprehension and (11) sub-skills for each main skill, the sub skills were prepared in Likert's three point scale to identify If each sub skill is "Very Important, "Important" and "Not Important" by ticking " $\sqrt{ }$ ".

For the EFL reading comprehension skills students at the second year should be able to:

\subsection{Pre- reading sub-skills:}

4.1 Try to guess the topic of the text. 
4.2 Predict what are the questions expected un all paragraph.

4.3 Guess the meaning of difficult words.

\subsection{During-reading sub-skills:}

5.1 Skim the text to get the main idea.

5.2 Scan the text for understanding more details.

5.3 paraphrase main ideas.

5.4 predict outcomes in the text.

5.5 infer meaning from the text.

\subsection{After-reading sub-skills:}

6.1 summarize the ideas of the text.

6.2 write the author's purpose.

6.3 draw conclusion about the text.

6.4 answer questions of the text.

6.5 agree or dis agree with the author.

6.6 problem solving in the text.

\section{A.4 The validity of the EFL reading comprehension checklist:}

An EFL reading comprehension checklist was submitted to a jury members of EFL staff members in curriculum and instruction $(n=7)$ (see Appendix A). to express the appropriate each main skill and sub-skill, determine the suitability of reading comprehension checklist for the sample of the study, add any necessary skills and omit un necessary skills.

For the modification of the EFL reading comprehension checklist Modifying: 1-Ask questions to answer questions or read for details.

2- drawing conclusion to draw conclusion.

3- recognize the author's purpose to determine the author's purpose.

Adding: 1-problem solving.

2- predict outcomes. 
3- Infer cause and effect.

Deletion: 1- summarize the main ideas because it is similar to summarize the text.

\section{A.5 The Final Form of the EFL reading comprehension skills checklist:}

After modifying the EFL reading comprehension checklist, the opinions of the jury members were put in the final form. The Final form has three main skills and (14) sub-skills. These added skills are infer cause and effect, predicting outcomes and problem solving (see Appendix B).

\section{B) The Reading comprehension test:}

\section{B.1 The purpose of Reading comprehension test:}

The reading comprehension test was prepared by the researcher, the researcher used the test as pre-posttest. It was prepared to measure EFL reading comprehension skills checklist with its main skills and sub skills in the English section second year students at the Faculty of Education to investigate the effectiveness of using digital reading strategies after applying the experimental treatment. The main purpose of the study is to identify the level of students before and after the treatment.

\section{B.2 Design of the study:}

The present study followed pre-posttest reading comprehension skills test

\section{B.3 Description of the test:}

The reading comprehension test was consisted of one passage which is suitable for students' interests and level. The test was consisted of one passage which covered all main skills and sub-skills identified by Jury member followed by 13 questions. The researcher made survey to tests in related studies with the same sample to identify main skills as literal, inferential, critical or evaluative sub-skills for the sample. Each 
question measures one sub- skill. Each question is different in the length of correct answer and the deep of question. The questions of the test were open-ended questions

\section{B.4 Piloting of the reading comprehension test:}

The researcher applied test to pilot sample $(\mathrm{N}=25)$ at the second year English language section at the faculty of Education, Benha university to investigate:

1- The suitability of the test level for all students.

2- The questions in the test were clear and understood.

3- All items of the test was clear .

4- The test questions cover the reading comprehension skills checklist. After applying the test the researcher calculated the time of the first learner answered the test and the last learner answered the test. The test's duration was about 60 to 75 minutes.

\section{B.4 procedures of the study:}

\section{Pre-test:}

The EFL Reading comprehension Pre-test was administrated to the implementation group of the study before the program. The sample was (25) students at English section second year at the faculty of Education before implementation of the program on $21^{\text {st }}$ May, 2019.

Post - test:

After teaching with digital reading strategies as program, the EFL Reading comprehension test re administrated to the same sample of the pre-test on $2^{\text {nd }}$ may, 2019 (N25) on the second year English section at the Faculty of Education. The post-test investigated using digital reading strategies. 


\section{B.5 The source of reading comprehension test:}

Jeffries, L., \& Mikulecky, B., S. (2007). Advanced reading power: Extensive Reading, Vocabulary Building, Comprehension Skills, Reading Faster. New York: Pearson

\section{B.6 validity of Reading Comprehension Skills test}

The test was submitted by (13) jury members in curricula and methodology (see Appendix A) to face validity of the test' questions and content for students in specialized course at English section .The researcher asked the jury to provide their judgment about the suitability of the test items for students' level, the test items reflect reading comprehension skills, the difficulty of the questions for English language students and the suggestions for adding or omitting. The validity of questions which represented the required skills. For the final form see $\operatorname{Appendix}(\mathbf{C})$

\section{B.7 The Reliability of the Test:}

For estimating the reliability of the EFL reading comprehension test. The researcher used test re-test method to estimate the reliability of reading comprehension test. The researcher administrated the test at the beginning of the second semester in February, 2019 to sample of second year English section at the faculty of Education $(\mathrm{N}=25)$. The researcher re applied the test again to the same sample after applying the program. The researcher applied pilot of the test on random sample and readministrated the test after a month to the same sample. The correlation co-efficient ( $r$ ) between the findings of the first and second application of the test was measured by using Pearson formula. The coefficient reliability was 0.893 which is significant at .01 level. So, the reliability co-efficient shows high reliability of the test.

\section{B.8 Scoring the EFL reading comprehension test:}

The EFL reading comprehension test is consisted of 13 questions. The questions were open-ended. The researcher put model 
answer for judging answers. The researcher developed a rubric to assess students answers to questions(see Appendix D). The rubric consisted of four items distributed as follows 4-3-2-1. The researcher adopted the rubric from Helwa (2010)The questions from 1 to 10 and question 12 takes four for each question. Question 11 takes 16 marks because it has four items. Question13 takes 20 marks because it has five items. The total mark of the test was 80 . The researcher used reliability for pre-posttest.

\section{C) Digital reading strategies:}

\section{C.1 Objectives of digital reading strategies:}

The objectives of using digital reading strategies for developing EFL reading comprehension skills as the implementation program for second year English language department students at Faculty of Education (Benha university) study reading comprehension as specialized course (For the program).So, students at the of the program will be able to:

- know what are digital reading strategies.

- recognize the importance for digital reading strategies.

- practice digital reading strategies.

- using internet in developing reading comprehension skills.

- read sentences and make conjunctions between sentences.

- Enjoy with every tool in digital reading.

- Scan the text to find specific information quickly.

- skim the text to get the main idea.

- infer or guess the meaning of unfamiliar words from using context clues.

- use dictionary for difficult words.

- answer questions for details.

- paraphrase the main ideas.

- determine the author's purpose.

- draw conclusions from the author's words.

- agree or disagree with the author. 


\section{C.2 Content of digital reading strategies's teacher guide:}

The researcher was taken the content from Read works digital as online plat form has variety of passages in all topics as political, religious, geography ,science and history ....etc. The platform was used in countries such as USA, Saudi Arabia and Egypt.

The program included (11) passages which contain all topics of students' interest and the level of students. The content of digital reading strategies' were depended on online on down loading passages and practicing all strategies with Kami, Power thesaurus, Using paraphrasing tool, hyperlinks which leads to variety of websites.

\section{C.3 Time duration of the experimental design:}

Digital reading strategies were implemented in the second semester of the academic year 2018-2019.It stated from28-3-2019 to 2 5-2019. It lasted for 6 weeks for two sessions a week, each session lasts for 60-70 minutes.

\section{C.4 The description of digital reading strategies:}

The program begins with orientation session to introduce reading comprehension skills, the importance of them. what are differences between electronic reading, on line reading and digital reading strategies 'definition, importance and digital reading strategies. The sessions from 2-11were instructional sessions for digital reading strategies and reading comprehension skills. The researcher introduced the strategy on each lesson an how to implement it digitally. In each lesson students practice strategy or more than one strategy. The researcher try to connect the strategy with reading comprehension skill in each session, the researcher modeled to students how to use it, ask them about their attention of how this strategy is effective on reading

- The researcher login read works digital as online plat form.

- The researcher makes class for students and give them verification code to $\log$ in the plat form.

- The researcher down load other programs as kami and power thesaurus as on line dictionary on computers from Google chrome to practice digital reading strategies 
- Students apply one strategy or more than one strategy with one reading comprehension skill or more than one.

- Students log in Read Works Digital and read the passage.

- Students use online programs as Kami, online dictionary, other tools to practice these strategies digitally according to review of literature and related studies defined digital reading strategies.

\section{C.6 Digital reading strategies framework:}

\begin{tabular}{|c|c|c|c|}
\hline $\begin{array}{c}\text { Session \& } \\
\text { date }\end{array}$ & objectives & materials & duration \\
\hline 21-3-2019 & $\begin{array}{c}\text { Pre-test reading comprehension } \\
\text { test }\end{array}$ & Handouts of the test & 70 minutes \\
\hline $\begin{array}{l}\text { Session (1) } \\
\text { Goal setting } \\
\text { \&introductory } \\
\text { session } \\
\text { 25-3-2019 }\end{array}$ & 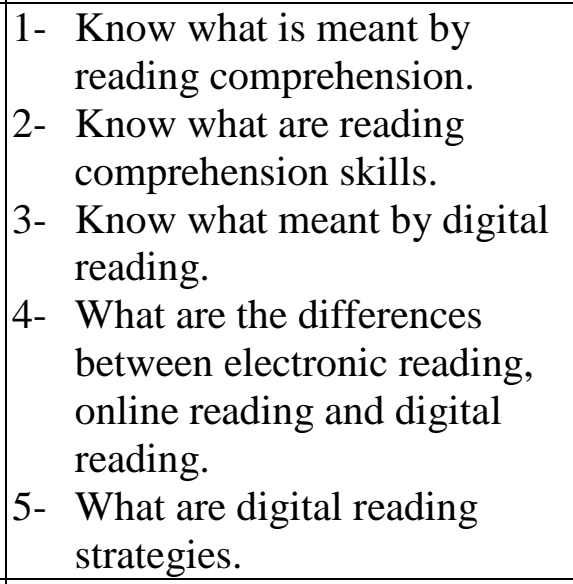 & Handouts' questions. & 60 minutes \\
\hline $\begin{array}{l}\text { Session (2) } \\
1-4-2019\end{array}$ & 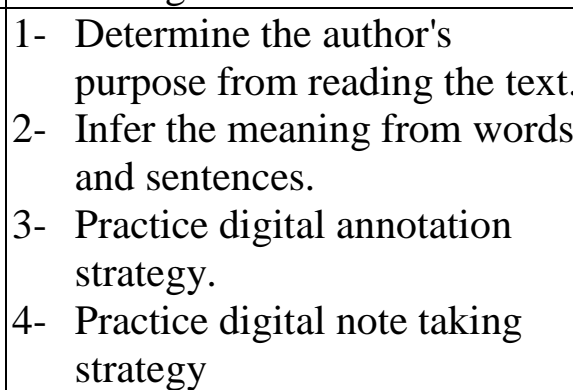 & $\begin{array}{c}\text { Read Works Digital \& } \\
\text { Kami }\end{array}$ & 75 minutes \\
\hline $\begin{array}{c}\text { Session (3) } \\
4-4-2019\end{array}$ & $\begin{array}{ll}\text { 1- } & \text { Use dictionary for looking up } \\
& \text { difficult words. } \\
\text { 2- } & \text { Draw conclusion about the } \\
& \text { text. } \\
\text { 3- } & \text { Use online dictionary as a } \\
& \text { strategy. }\end{array}$ & $\begin{array}{c}\text { Read Works Digital, } \\
\text { handouts and Power } \\
\text { thesaurus } \\
\text { online dictionary. }\end{array}$ & 60 minutes \\
\hline $\begin{array}{c}\text { Session (4) } \\
8-4-2019\end{array}$ & $\begin{array}{l}\text { 1- } \text { Infer cause and effect. } \\
\text { 2- } \\
\text { Accessing hyperlinks as a } \\
\text { strategy. }\end{array}$ & $\begin{array}{c}\text { Read Works Digital, } \\
\text { handouts, Hyperlinks of } \\
\text { some words or phrases } \\
\text { lead to images, videos } \\
\text { and audios. }\end{array}$ & 75 minutes \\
\hline
\end{tabular}




\begin{tabular}{|c|c|c|c|}
\hline $\begin{array}{c}\text { Session \& } \\
\text { date }\end{array}$ & objectives & materials & duration \\
\hline $\begin{array}{l}\text { Session }(5) \\
11-4-2019\end{array}$ & $\begin{array}{ll}\text { 1- } & \text { Skim the text to get the main } \\
\text { idea. } \\
\text { 2- } \\
\text { Scan the text to find specific } \\
\text { information. } \\
\text { 3- } \\
\text { Digital highlight as strategy. } \\
\text { Digital underline as a } \\
\text { strategy. } \\
\text { 5- } \\
\text { Digital comment as a } \\
\text { strategy. }\end{array}$ & $\begin{array}{l}\text { Kami, handouts } \\
\text { and Read Works } \\
\text { Digital. }\end{array}$ & 75 minutes \\
\hline $\begin{array}{c}\text { Session (6) } \\
15-4-2019\end{array}$ & $\begin{array}{l}\text { 1- Summarize the text as skill. } \\
\text { 2- Summarize the text online as } \\
\text { a strategy. }\end{array}$ & $\begin{array}{l}\text { Read Works Digital, } \\
\text { handouts, Kami and AI } \\
\text { Summarizer tool. }\end{array}$ & 60 minutes \\
\hline $\begin{array}{l}\text { Session (7) } \\
18-4-2019\end{array}$ & $\begin{aligned} \text { 1- } & \text { Paraphrase main ideas as a } \\
& \text { skill. } \\
\text { 2- } & \begin{array}{l}\text { Paraphrase or re state ideas } \\
\text { online as a strategy. }\end{array}\end{aligned}$ & $\begin{array}{l}\text { Read Works Digital, } \\
\text { handouts and } \\
\text { paraphrasing tool on } \\
\text { line }\end{array}$ & 70 minutes \\
\hline $\begin{array}{l}\text { Session (8) } \\
22-4-2019\end{array}$ & $\begin{array}{l}\text { 1- } \quad \text { Agree or dis agree with } \\
\text { the author. } \\
2-\quad \text { Draw figures, diagrams } \\
\text { and shapes as a strategy. }\end{array}$ & $\begin{array}{l}\text { Read Works Digital, } \\
\text { handouts and Kami }\end{array}$ & 70 minutes \\
\hline $\begin{array}{l}\text { Session (9) } \\
23-4-2019\end{array}$ & $\begin{array}{ll}\text { 1- } & \text { Answer questions for details } \\
\text { 2- } & \text { Extract data from graphs and } \\
& \text { diagrams. } \\
\text { 3- } & \text { Scan hypertext as a strategy. }\end{array}$ & $\begin{array}{c}\text { Read Works Digital, } \\
\text { handouts, diagrams and } \\
\text { figures online texts and } \\
\text { hyperlinks }\end{array}$ & 75 minutes \\
\hline $\begin{array}{l}\text { Session (10) } \\
27-4-2019\end{array}$ & $\begin{array}{l}\text { 1- } \begin{array}{l}\text { Predict outcomes from the } \\
\text { text. } \\
\text { 2- } \\
\text { Access hypermedia as audio, } \\
\text { videos and images. }\end{array} \\
\end{array}$ & $\begin{array}{l}\text { Read Works Digital, } \\
\text { handouts, Audios, } \\
\text { videos and images' } \\
\text { hyperlinks. }\end{array}$ & 70 minutes \\
\hline $\begin{array}{l}\text { Session (11) } \\
\text { 30-4-2019 }\end{array}$ & $\begin{array}{l}\text { 1- } \text { Problem solving as a skill. } \\
\text { 2- } \text { Re- reading online texts. } \\
\text { 3- } \text { Digital comment. }\end{array}$ & $\begin{array}{l}\text { Read Works Digital, } \\
\text { handouts. }\end{array}$ & 60 minutes \\
\hline $\begin{array}{l}\text { Session (12) } \\
2-5-2019\end{array}$ & $\begin{array}{l}\text { Post-test reading comprehension } \\
\text { test. }\end{array}$ & handouts & 75 minutes \\
\hline
\end{tabular}

\section{C.5 Sources of digital reading strategies:}

The researcher surveyed the previous and related studies and identified digital reading strategies were applied as the following sources Anderson (2003), Chen (2009), Zarrabi (2015) and Rodrigue (2017). 


\section{C.6 The instructional aids:}

The implementation included in EFL reading tasks and activities which were derived from Read Works Digital as online platform with variety of reading comprehension passages with all levels and variety of topics (political, religious, science), Kami as PDF program for applying some digital reading strategies, Power thesaurus, you tubes, hyperlinks and hypermedia, AI Summarizer and using paraphrasing tool.

\section{D) The teacher and the student roles:}

The teacher has variety of roles in each stage of reading as helper, guide, supporter and observer for students.

\section{D.1 Teacher's role:}

\section{Pre-reading stage:}

1- Teacher defines digital reading strategy in every lesson.

2- Teacher asks students about the skill before illustrating it.

3- Teacher revises the previous skill and the previous digital reading strategy.

4- Teacher introduces the topic of the lesson.

\section{During-reading stage:}

1- Teacher asks students to login the passage assigned.

2- Teacher illustrates the tool in the lesson

3- Teacher explains how to implement the strategy with this tool or program.

4- Teacher explains the skill in reading comprehension and how to practice it.

5- Teacher observes students and guide them all the lesson.

\section{After - reading stage:}

1- Teacher asks students to answer questions on the passage.

2- Teacher gives students assignment related to the skill in each lesson.

3- Teacher asks students to summarize the lesson by asking them the strategy and the skill. 
4- Teacher asks students to explain the tool or the program and how they use from it in applying the strategy.

5- Teacher observed them and evaluated them online

\section{D.2 Students' roles:}

\section{Before- reading:}

1- Students begin to think about the strategy in the lesson and the skill the teacher told them .

2- Students begin to ask teacher about supported tools in the lesson.

3 - Students makes brainstorming to make connection between the strategy and the skill.

4- Students log in the platform which contains the passages.

\section{During reading:}

1- Students begin to read the passage online.

2- Students begin to apply the strategy in each lesson with using the tool.

3- Students make predictions while reading

4- Students try to use the strategy to facilitate the skill.

5- Student extract the skill from the passage.

\section{After reading:}

1- Students answer questions online in the platform.

2- Students work with each other to examine understanding after finishing questions online.

3- Students answer offline assignment about the required skill in this lesson.

4- Students listen to feedback about offline assignment.

\section{D.3 Evaluation:}

Evaluation is online evaluation during the implementation this is which called formative assessment and offline evaluation after the implementation which is called summative evaluation.

Chapter 4 shows the findings of the post-test in their relation to using digital reading strategies. The following is a detailed analysis of digital reading strategies implementation. 


\section{Discussions of the results}

Based on the previously mentioned results of the study, it is clear that the student performance in reading comprehension skill was improved especially in the posttest treatment. The student achieved the highest level of comprehension skills compounding with the pretreatment. The gain may be due to the fact that digital reading strategies had some influential factors of the students as follows:

- Electronic literacy knowledge and experience ELLS.

- Teacher grades for online reading strategies and text reading.

- The language of online text.

- Accessing a web page.

- Adjusting the reading pattern

- Dialoguing- pairs- pears.

- Inferring from the text.

- Making connection.

- Monitoring comprehension.

- Using computer skills and devices.

This results is consisted with kim (2017). The results also revealed that the students were able to get through all the texts online/offline and were also able to absorb, integrate, synthesize, respond and extend their understanding and comprehension to all texts. This is reflected in this post-performance and it may be attribute to the fact that digital reading strategies helped the students simultaneously:

- Activate background knowledge and set a purpose for reading.

- Organize knowledge

- Make inference

- Visualize.

- Figure out the meaning of unknown words.

- Ask questions.

- Figure out what is important..

At the same time, digital reading strategy focused students attention on instruction in prior knowledge, text structure and the content that enabled students to comprehend text more proficiency. This result is consisted with Irvim et al. (2002). 
The findings of this study substitute to the growing evidence base on the positive motivational effects of computer assisted reading instruction on students especially these who had reading difficulty during this classes on reading instruction, then, digital reading helps students go beyond this burden through:

- Focusing on the process of comprehension and moving to independent learning.

- Providing sample with amount of time for reading.

- Provide opportunities to learn collaboratively and talk about reading.

- Facilitating comprehension instructions before, during and after reading.

- Thinking aloud and sharing teachers.

- Reinforcing and developing ability through writing.

- Assisting standards to use visual information to comprehend text.

- Making assessment compatible with kinds of learning encouraged digital reading.

All these aspects helped the students access the texts from online/ offline and supported this understanding of the text through the use of different supported tools. This result is consisted with Ciampa (2012).

The results of the study indicated that the students' progress reflected performance in posttest was greater than performance in pretest. This may be due to the fact that integration of two contexts(onlineoffline) provide the opportunity for students to engage in proficient, independent processing at a level of success that allow to expand their reading power. Also, in digital reading lessons, the teacher provided a sequence of high quality engaging texts that supported students' progress at all levels of comprehension. Digital reading strategies helped students increase the quality of independent reading because it:

- Allows the teacher to match texts to students current reading abilities.

- Provides a strong instructional context with teacher can support students' success for processing challenging texts.

- Allows the teacher selects texts that alter learning opportunities and will engage students. This result is consisted with pinnel and Fommats (2012). 


\section{Discussions of the results}

- The results of the study revealed that there is improvement in the student high level of comprehension practice especially in decoding and encoding, critical and creative skills composing with the pre-test results.

- The students were able to infer the meaning from the texts directly, decode the meaning and analyze it. This is reflected in this post test. This improvement may be due to or can be attributed to digital reading which enabled them to engage with texts in a diverse range of space using screen interfaces. Students' engagement with the digital texts as well as offline texts helped them develop a range of new skills which are required in the move to the participators due to:

- Play the capacity to the experiment with one's surrounding as a form of problem- solving.

- Performance - the ability to adopt alternative identities for the purpose of improvisation and discovery.

- Simulation: the ability to interpret and construct dynamic model of the comprehension process.

- Appropriateness: the ability to meaningfully comprehend media content.

- Multitasking: the ability to scan text and focus on silent details.

- Distributed cognition: the ability to interact meaningfully with tools that expand mental capacities.

\section{Results of the study and its discussions:}

This chapter deals with the results of the present study, its statistical degree and discussions of the results.

\section{The results:}

\section{The first hypothesis:}

This hypothesis states that there are significant differences among the main score of the students in the pre-post testing in the first of reading skill which is using dictionary. The difference is in favor of the post-testing. To verify this hypothesis. The researcher used t.test to 
measure the differences may the mean scores of the study participants. Pre-test the following table shows this table(1)T. Test between the mean score of the pre-post testing in dictionary use

\begin{tabular}{|c|c|c|c|c|c|c||}
\hline Dictionary use & N. & mean & St. D & T. & df. & sig \\
\hline \hline Post- test & 25 & 3.3600 & .75719 & 6.336 & 24 & .01 \\
\hline Pre-test & 25 & 1.8800 & 1.04363 & 6.336 & 24 & .01 \\
\hline
\end{tabular}

This table shows that there are significant differences between the mean scores of the students in the dictionary use skill in the pre-post testing. This difference was significant at .01 in favor of the post-testing which indicates that the first hypothesis was achieved.

\section{The second hypothesis:}

This hypothesis states that there are statistically significant differences among the main score of the students in the pre-post testing in the second of reading skill which is skimming the text. To verify this hypothesis $\mathrm{T}$. test is use. The following table shows that:

table(2)T. Test between the mean score of the pre-post testing in skimming the text skill

\begin{tabular}{|c|c|c|c|c|c|c||}
\hline Skimming the text & N. & mean & St. D & T. & df. & sig \\
\hline \hline Post- test & 25 & 3.4400 & .65064 & 9.453 & 24 & .01 \\
\hline Pre-test & 25 & 1.2400 & .95873 & 9.453 & 24 & .01 \\
\hline
\end{tabular}

This table shows that there are statistically significant differences between the mean scores of the students in skimming the text skill in the pre-post testing. This difference was significant at .01 in favor of the post-testing which indicates that the second hypothesis was achieved.

\section{The third hypothesis:}

This hypothesis states that there are statistically significant differences among the mean score of the students in the pre-post testing in the third of reading skill which is the author's purpose. To verify this hypothesis T. test is use. The following table shows that:

\begin{tabular}{|c|c|c|c|c|c|c|}
\hline \hline The author's point of view & N. & mean & St. D & T. & df. & sig \\
\hline \hline Post- test & 25 & 3.6400 & 1.11355 & 5.731 & 24 & .01 \\
\hline Pre-test & 25 & 1.7200 & 1.36229 & 5.731 & 24 & .01 \\
\hline
\end{tabular}


This table shows that there are statistically significant differences between the mean scores of the students in the author's purpose skill in the pre-post testing. This difference is in the favor of the post-testing. The level of significant is .01 which is in favor of the post-testing. that the third hypothesis was achieved.

\section{The fourth hypothesis:}

This hypothesis states that there are statistically significant differences among the mean score of the students in the pre-post testing in the fourth of reading skill which is the answer questions for details and scan the text to get information. The following table shows that:

\begin{tabular}{|c|c|c|c|c|c|c|}
\hline $\begin{array}{c}\text { Answer questions for } \\
\text { details and scan the text } \\
\text { to get information }\end{array}$ & N. & mean & St. D & T. & df. & sig \\
\hline \hline Post- test & 25 & 3.5200 & 1.08474 & 3.582 & 24 & .01 \\
\hline Pre-test & 25 & 2.3800 & 1.31719 & 3.582 & 24 & .01 \\
\hline
\end{tabular}

This table shows that there are statistically significant differences between the mean scores of the students in answering the questions for details skill in the pre-post testing. This difference is in the favor of the post-testing. The level of significant is .01 which is in favor of the posttesting. that the fourth hypothesis was achieved.

\section{The fifth hypothesis:}

This hypothesis states that there are statistically significant differences among the mean score of the students in the pre-post testing in the fifth of reading skill which is infer the meaning. The following table shows that:

\begin{tabular}{|c|c|c|c|c|c|c|}
\hline Infer the meaning & N & mean & St. D & T. & df & sig \\
\hline \hline Post-test & 25 & 3.2800 & .79162 & 7.729 & 24 & .01 \\
\hline Pre-test & 25 & 1.1200 & 1.04363 & 7.729 & 24 & .01 \\
\hline
\end{tabular}

This table shows that there are statistically significant differences between the mean scores of the students in infer the meaning skill in the pre-post testing. This difference is in the favor of the post-testing. The 
level of significant is .01 which is in favor of the post-testing. that the fifth hypothesis was achieved.

\section{The sixth hypothesis:}

This hypothesis states that there are statistically significant differences among the mean score of the students in the pre-post testing in the sixth of reading skill which is predicting outcomes. The following table shows that:

\begin{tabular}{|c|c|c|c|c|c|c|}
\hline Predicting outcomes & N & mean & St D & t. & Df. & sig \\
\hline \hline Post-test & 25 & 3.8800 & .43970 & 5.481 & 24 & .01 \\
\hline Pre-post & 25 & 2.40000 & 1.436144 & 5.481 & 24 & .01 \\
\hline
\end{tabular}

This table shows that there are statistically significant differences between the mean scores of the students in skill in the pre- predicting outcomes post testing. This difference is in the favor of the post-testing. The level of significant is .01 which is in favor of the post-testing. that the sixth hypothesis was achieved.

\section{The seventh hypothesis: $\square$}

This hypothesis states that there are statistically significant differences among the mean score of the students in the pre-post testing in the seventh of reading skill which is drawing conclusion and paraphrasing main ideas. The following table shows that:

\begin{tabular}{|c|c|c|c|c|c|c|}
\hline $\begin{array}{c}\text { Drawing conclusion and } \\
\text { paraphrasing main ideas }\end{array}$ & N & mean & St D & t. & Df. & sig \\
\hline \hline Post-test & 25 & 3.7600 & .83066 & 9.058 & 24 & .01 \\
\hline Pre-post & 25 & 1.5400 & 1.22406 & 9.058 & 24 & .01 \\
\hline
\end{tabular}

This table shows that there are statistically significant differences between the mean scores of the students in drawing the conclusion and paraphrasing main ideas skill in the pre-post testing. This difference is in the favor of the post-testing. The level of significant is .01 which is in favor of the post-testing. that the seventh hypothesis was achieved.

\section{The eighth hypothesis:}

This hypothesis states that there are statistically significant differences among the mean score of the students in the pre-post testing in the eighth of reading skill which is agree or disagree skill. The following table shows that: 


\begin{tabular}{|c|c|c|c|c|c|c||}
\hline Agree or disagree & N & mean & St D & t. & Df. & sig \\
\hline \hline Post-test & 25 & 3.6400 & .7000 & 7.509 & 24 & .01 \\
\hline Pre-post & 25 & 1.0600 & 1.41657 & 7.509 & 24 & .01 \\
\hline
\end{tabular}

This table shows that there are statistically significant differences between the mean scores of the students in agree or disagree skill in the pre-post testing. This difference is in the favor of the post-testing. The level of significant is .01 which is in favor of the post-testing. that the eighth hypothesis was achieved.

\section{The ninth hypothesis:}

This hypothesis states that there are statistically significant differences among the mean score of the students in the pre-post testing in the ninth of reading skill which is problem solving skill. The following table shows that:

\begin{tabular}{|c|c|c|c|c|c|c|}
\hline \hline Problem solving skills & N & mean & St D & t. & Df. & sig \\
\hline \hline Post-test & 25 & 3.3600 & .70000 & 5.818 & 24 & .01 \\
\hline Pre-post & 25 & 1.4600 & 1.13578 & 5.818 & 24 & .01 \\
\hline
\end{tabular}

This table shows that there are statistically significant differences between the mean scores of the students in problem solving skill in the pre-post testing. This difference is in the favor of the post-testing. The level of significant is .01 which is in favor of the post-testing. that the ninth hypothesis was achieved.

\section{The tenth hypothesis:}

This hypothesis states that there are statistically significant differences among the mean score of the students in the pre-post testing in the tenth of reading skill which is summarize the text and infer cause and effect skill. The following table shows that:

\begin{tabular}{|c|c|c|c|c|c|c||}
\hline $\begin{array}{c}\text { Summarize the text and } \\
\text { infer cause and effect }\end{array}$ & N & mean & St D & t. & Df. & sig \\
\hline \hline Post-test & 25 & 3.8000 & 1.47196 & 4.317 & 24 & .01 \\
\hline Pre-post & 25 & 1.8200 & 1.36076 & 4.317 & 24 & .01 \\
\hline
\end{tabular}

This table shows that there are statistically significant differences between the mean scores of the students in summarize the text skill in the pre-post testing. This difference is in the favor of the post-testing. The level of significant is .01 which is in favor of the post-testing. that the tenth hypothesis was achieved. 


\section{The eleventh hypothesis: $\square$}

This hypothesis states that there are statistically significant differences among the mean score of the students in the pre-post testing in the eleventh of reading skill which is infer the meaning skill. The following table shows that:

\begin{tabular}{|c|c|c|c|c|c|c||}
\hline Infer the meaning & N & mean & St D & t. & Df. & sig \\
\hline \hline Post-test & 25 & 11.8400 & 3.23625 & 9.178 & 24 & .01 \\
\hline Pre-post & 25 & 4.2000 & 2.91548 & 9.178 & 24 & .01 \\
\hline
\end{tabular}

This table shows that there are statistically significant differences between the mean scores of the students in infer the meaning skill in the pre-post testing. This difference is in the favor of the post-testing. The level of significant is .01 which is in favor of the post-testing. that the tenth hypothesis was achieved.

\section{The twelfth hypothesis:}

This hypothesis states that there are statistically significant differences among the mean score of the students in the pre-post testing in the twelfth of reading skill which is context clauses skill. The following table shows that:

\begin{tabular}{|c|c|c|c|c|c|c|}
\hline Context clauses & N & mean & St D & t. & Df. & sig \\
\hline \hline Post-test & 25 & 1.4400 & 1.44568 & 2.623 & 24 & .01 \\
\hline Pre-post & 25 & .6600 & .98658 & 2.623 & 24 & .01 \\
\hline
\end{tabular}

This table shows that there are statistically significant differences between the mean scores of the students in context clauses skill in the pre-post testing. This difference is in the favor of the post-testing. The level of significant is .01 which is in favor of the post-testing. that the tenth hypothesis was achieved.

\section{The thirteenth hypothesis :}

This hypothesis states that there are statistically significant differences among the mean score of the students in the pre-post testing in the tenth of reading skill which is context clauses skill. The following table shows that:

\begin{tabular}{|c|c|c|c|c|c|c|}
\hline Paraphrase main ideas & N & mean & St D & t. & Df. & sig \\
\hline \hline Post-test & 25 & 17.4800 & 5.37060 & 3.095 & 24 & .01 \\
\hline Pre-post & 25 & 13.8400 & 5.80718 & 3.095 & 24 & .01 \\
\hline
\end{tabular}

